\title{
The Influence of Selected ECAP-Processing Routes on the Material Properties
} of Magnesium Elektron 675

\author{
M. Bleckmann ${ }^{a^{*}}$, M. Eichhorst ${ }^{b}$, M. Schuch $^{a}$, W. Kreuzer ${ }^{a}$, V.H. Hammond ${ }^{\mathrm{a}, 1}$, C. \\ Spiller $^{\text {b }}$, L.W. Meyer ${ }^{\text {b }}$, N. Herzig ${ }^{\text {b }}$ \\ ${ }^{a}$ Wehrwissenschaftliches Institut für Werk- und Betriebsstoffe (WIWeB), \\ Institutsweg 1, 85435 Erding, Germany \\ Corresponding author. Phone: +49-8122-9590-3260, Fax: +49-8122-9590- \\ 3202, E-mail address: MatthiasBleckmann@bundeswehr.org \\ ${ }^{\mathrm{b}}$ Nordmetall GmbH, Materials and Impact Engineering, Hauptstraße 16, \\ 09221 Adorf/Erzgebirge, Germany
}

\section{Abstract:}

Due to the continued interest in reducing weight in both automobile and aerospace structures, interest has grown in magnesium based alloys as a possible materials solution. Despite this interest, these alloys have not been widely utilized due to their relatively poor mechanical properties in comparison to other material systems. However, recent research has clearly indicated that improved mechanical properties can be achieved in these alloys through the use of severe plastic deformation processing methods. In this report, we examine the influence of equal channel angular pressing on the mechanical response of Elektron 675, a Mg-Gd-Y alloy. Results indicate that an appreciable increase in total elongation and absorbed energy can be obtained depending on the selected processing route. However, these improvements in elongation are somewhat offset by a slight reduction in tensile strength. The observed mechanical response is explained through microstructural analysis as well as texture measurements.

\section{Keywords: Magnesium alloys, Equal channel angular pressing, Mechanical characterization, EBSD}

\section{Introduction}

As a result of increased concerns regarding fuel efficiency as well as stricter environmental regulations, there is an increased demand for lightweight materials suitable for use in the automotive and aerospace industries. Because of the stringent ${ }^{1}$ Permanent Address: Weapons and Materials Research Directorate, United States Army Research Laboratory, Aberdeen Proving Ground, MD, USA. 
safety requirements associated with these industries, the considered material must possess high strength and toughness as well as the requisite low density. Magnesium (Mg), with a 30\% lower density than aluminum, has often been considered an excellent candidate. However, the use of pure $\mathrm{Mg}$ is severely limited because of its low tensile strength $(\sim 100-200 \mathrm{MPa})$, poor ductility $(\sim 5-8 \%$ elongation), and a sensitivity to corrosion. The poor mechanical properties of $\mathrm{Mg}$ alloys are due to limited room temperature deformation mechanisms available in its hexagonal close packed crystal structure [1]. As a result, substantial efforts have been made to develop high performance $\mathrm{Mg}$ alloys through the use of elemental additions, thermo-mechanical processing, or a combination of the two.

In this respect, the introduction of rare earth (RE) elements has been shown to have a profound influence on the properties of magnesium. Indeed, it has been demonstrated that the addition of elements such as Yttrium $(\mathrm{Y})$ and Gadolinium (Gd) resulted in improved mechanical properties [2, 3, 4]. As could be expected, the improvement in strength is mainly caused by solid solution strengthening or precipitation hardening due to the formation of $\mathrm{Mg}-\mathrm{Y}$ or $\mathrm{Mg}-\mathrm{Gd}$ intermetallic phases such as $\mathrm{Mg}_{24} \mathrm{Y}_{5}$ or $\mathrm{MgGd}_{5}$. Moreover, as the equilibrium concentration of the intermetallic phase depends on temperature [5], the mechanical properties can be easily adjusted by a deliberate heat treatment $[3,4,6,7]$. The improvement in ductility can be quite dramatic, as seen in the study by Sandlöbes et al., who showed that the addition of 3 weight percent (wt.\%) $\mathrm{Y}$ to pure $\mathrm{Mg}$ improved the maximum elongation by a factor of five [8]. The improvement in ductility is attributed to the

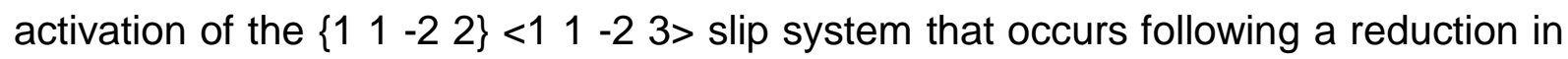
its stacking fault energy and, hence, its critical resolved shear stress [8].

As a result of these observations, several studies have examined the properties obtained by adding a combination of $R E$ elements to $M g[2-4,6,7]$. In particular, alloys from the ternary system Mg-Gd-Y possess outstanding mechanical properties compared to other $\mathrm{Mg}$ alloys like AZ31 or WE43. In particular, Elektron 675 (Magnesium Elektron, UK) has a typical ultimate tensile strength of $410 \mathrm{MPa}$ and a maximum elongation at failure of about $9 \%$ [9]. These properties, in combination with its low density, may enable its use in aerospace and automotive applications as well as armor protection applications $[9,10,11]$. 
In addition to improvements gained through elemental additions, the use of microstructural engineering based on severe plastic deformation processing, e.g. equal channel angular pressing (ECAP), offers the possibility of further improvements in material properties. In contrast to cubic metals, strength increases achieved in $\mathrm{Mg}$ alloys through grain size reduction (e.g., Hall-Petch effects) are typically negated by a reduction in strength due to the alignment of the $\{0001\}$ planes parallel to the ECAPdie during processing $[12,13]$. However, it has been shown that the addition of $Y$ [8] and/or other RE elements leads to a distortion of the alignment of these planes by additional slip systems and the formation of shear bands. Thus, it is possible that ECAP processing of E675 would enhance not only the ductility but also the tensile strength of the alloy.

Surprisingly, to date, there has been only a limited number of studies on the properties and performance of E675 following ECAP processing. Early work by Twier and co-workers examined the influence of extrusion temperature and velocity on the microstructure and mechanical properties [14, 15]. Working on a closely related alloy (Mg-Gd-Y-Zr), Zhang et al. [16] found that the microstructure after ECAP processing contained large grains surrounded by necklace-like areas formed by finer grains. Increasing the number of ECAP passes resulted in an increased amount of fine grains. In general, it was observed that the strength of the material was enhanced by the number of ECAP passes, whereas an increase in ductility was caused by texture development.

Based on these results, a limited study was performed to evaluate the effectiveness of ECAP at improving both the strength and ductility of E675 through microstructural and textural refinement. The simplest ECAP recipe used was one pass at $325^{\circ} \mathrm{C}$, as an initial effort indicated such a treatment resulted in improved ductility in the E675 alloy [17]. However, the route of primary interest was based on a temperature step down method that has been shown to result in significant microstructural refinement and property improvements in AZ31 [18-21] as well as ZK60 [22, 23]. In order to investigate the potential of such a method for $\mathrm{E} 675$, a simple 4 pass recipe consisting of $2 \mathrm{C} / 325{ }^{\circ} \mathrm{C}$ followed by $2 \mathrm{C} / 300{ }^{\circ} \mathrm{C}$ was used. Due to its limited scope, this study does not attempt to provide a fully optimized ECAP processing approach. Rather, it is hoped that the understanding gained from this effort would provide an initial foundation upon which such optimization could be based. 


\section{Materials and methods}

\section{a. Material}

Magnesium Elektron alloy E675 is a high performance alloy that contains appreciable levels of both yttrium and light rare earth elements. These additions, along with a small amount of zirconium, provide the alloy with both solid solution strengthening as well as precipitation hardening. As a result, the alloy possesses a high tensile strength at room and elevated temperatures.

Extruded bars of E675 (22.2 x $\left.22.2 \times 1000 \mathrm{~mm}^{3}\right)$ were received in the T5 condition (elevated temperature age hardening). The chemical composition of the alloy (Table 1) was measured using inductively coupled plasma optical emission spectrometry (ICP-OES). In order to provide a benchmark for the results, the mechanical properties of the E675 alloy are compared with AZ31, a well-known solid-solution strengthened alloy. For this study, AZ31 was obtained as a rolled plate with a thickness of about $15 \mathrm{~mm}$. The chemical composition of the plate was measured by spectroscopic analysis (DIN 51009), with the results shown in Table 2.

Table 1: Chemical composition of E675.

\begin{tabular}{|c|c|c|c|c|c|c|c|c|}
\hline Element & $\mathrm{Mg}$ & $\mathrm{Gd}$ & $\mathrm{Y}$ & $\mathrm{Zr}$ & $\mathrm{Th}$ & $\mathrm{Nd}$ & $\mathrm{Ce}$ & Other \\
\hline wt. \% & 87.3 & 6.5 & 5.6 & 0.4 & 0.03 & 0.09 & 0.01 & 0.07 \\
\hline
\end{tabular}

Table 2: Chemical composition of AZ31.

\begin{tabular}{|c|c|c|c|c|c|c|c|c|}
\hline Element & $\mathrm{Mg}$ & $\mathrm{Al}$ & $\mathrm{Zn}$ & $\mathrm{Mn}$ & $\mathrm{Si}$ & $\mathrm{Fe}$ & $\mathrm{Cu}$ & $\mathrm{Ni}$ \\
\hline wt. \% & 95.69 & 2.87 & 1.06 & 0.37 & 0.01 & $<0.0012$ & $<0.0005$ & $<0.0015$ \\
\hline
\end{tabular}

Starting blanks for ECAP processing were taken from the middle of the rolled AZ31 plate in an orientation transverse to the rolling direction. These blanks, as well as the extruded E675 bars, were then machined by milling into bars with dimensions of approximately $15 \mathrm{~mm} \times 15 \mathrm{~mm}$ and a length of $120 \mathrm{~mm}$. A minimum of $10 \mathrm{~mm}$ was 
removed from the end of the bars in order to ensure the homogeneity of the initial microstructure.

\section{b. ECAP process}

The ECAP process was performed using an ECAP tool with an outer angle of $\psi=4^{\circ}$ and an inner angle of $\phi=90^{\circ}$ (Figure 1), resulting in an equivalent plastic strain of $\varphi$ $=1.1$ in each pass [18]. The pressing velocity was about $5 \mathrm{~mm} / \mathrm{min}$.

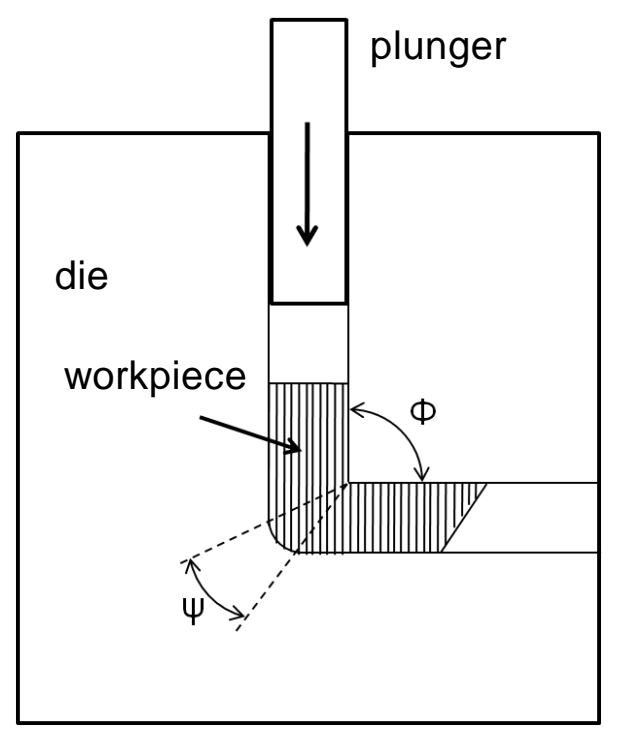

Figure 1: Principle of the ECAP process [13].

As indicated previously, two ECAP routes were used in this study. The first was simply one pass at $325^{\circ} \mathrm{C}$, while the second route was $2 \mathrm{C} / 325^{\circ} \mathrm{C}+2 \mathrm{C} / 300{ }^{\circ} \mathrm{C}$. In ECAP processing, route $\mathrm{C}$ designates a $180^{\circ}$ rotation around the longitudinal axis of the bar after each pass. Moreover, in the second route, the two passes at $325^{\circ} \mathrm{C}$ are intended to homogenize the microstructure by removing the basal texture present in the as-received extruded material. The step-down in temperature for the last two passes is designed to reduce the amount of grain growth due to recrystallization during the ECAP pass, thereby resulting in a more refined microstructure.

The workpieces were pre-heated at $325^{\circ} \mathrm{C}$ for ten minutes prior to ECAP processing. For samples processed using the multi-pass recipe, the sample was immediately reloaded following the completion of one pass and allowed to pre-heat for ten minutes prior to the beginning of the next pass. After all passes were completed, the workpieces were allowed to cool to room temperature in ambient air. This 
experimental procedure resulted in a typical total processing time of approximately 45 minutes. In an effort to separate ECAP induced changes from those resulting from the elevated temperature exposure, a set of E675 samples were subjected to an annealing treatment approximately equivalent to the total processing time (e.g., 45 minutes $/ 325^{\circ} \mathrm{C}$ ). This information, as well as sample designations used throughout the paper, is summarized in Table 3 .

Table 3: Thermo-mechanical processing parameters for E675.

\begin{tabular}{|c|c|c|c|c|}
\hline Identification & Route & Passes & $\begin{array}{c}\text { Temperature } \\
{\left[{ }^{\circ} \mathrm{C}\right]}\end{array}$ & $\begin{array}{c}\text { Pressing } \\
\text { velocity } \\
{[\mathrm{mm} / \mathrm{min}]}\end{array}$ \\
\hline E675_AR & - & - & - & - \\
\hline E675_HT & - & - & $325(45 \mathrm{~min})^{1}$ & - \\
\hline E675_C & - & 1 & 325 & 5 \\
\hline E675_4C & C & 2 & 325 & 5 \\
\end{tabular}

${ }^{1}$ Heat treatment time of 45 minutes was chosen as it is the approximate duration of the total processing time for a single pass in ECAP processing.

The ability to ECAP process the E675 alloy is shown in Error! Reference source not found.. Processed using the recipe E675_4C, the bar does not show any noticeable surface defects or flaws. Bars processed for a single pass were similar in appearance.

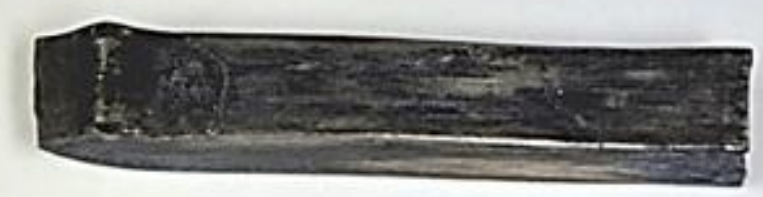

Figure 2: E675 after ECAP processing, E675_4C.

\section{c. Mechanical properties}

To ensure direct comparison to results published in the literature (e.g., $[12,13])$, the mechanical properties were investigated by quasi-static tensile tests (strain rate $10^{-3}$ 
$\mathrm{s}^{-1}$ ) at room temperature. In accordance with standard DIN 50125, tensile specimens with a gauge length of $10.5 \mathrm{~mm}$ and a gauge diameter of $3.56 \mathrm{~mm}$ were machined in longitudinal direction from the billets. In addition, tensile tests at a strain rate of approximately $1000 \mathrm{~s}^{-1}$ were performed using a rotating wheel machine. Due to the high energy capacity of the test frame relative to the tested sample, the test velocity is nearly constant up to failure even for high strength and/or high toughness materials. In order to accurately measure the yield stress, strain gauges were used to measure the elastic and plastic deformation up to 2 or $3 \%$ elongation. At higher deformations, the strain measurements were carried out using an electro-optical extensometer with a bandwidth of $400 \mathrm{kHz}$.

Because slight oscillations might be observed at low strains $(<0.5 \%)$ in the engineering stress-strain curve during the high rate testing, it is a common practice to report the yield strength measured at $1 \%$ strain rather than at $0.2 \%$, as is customarily done in quasi-static testing. In doing so, a more reliable strength value is obtained as any measurement artifacts induced by these oscillations are minimized or avoided. Consequently, in order to compare the yield strengths obtained from the two testing conditions, the decision was made to use the same degree of strain (1\%) for determining the yield strength in the samples tested in quasi-static conditions.

\section{d. Microstructure}

Grain size measurements were performed on specimens oriented transverse to the pressing direction. After being ground using 4000 grit paper, the samples were sequentially polished using $3 \mu \mathrm{m}$ MD-Nap, $1 \mu \mathrm{m}$ MD-Nap and $0.2 \mu \mathrm{m}$ water-free silica suspensions. As a finishing step, the samples were etched with $2 \%$ nitric acid. The grain size was characterized by linear interceptions of grain boundaries.

\section{e. Texture, phase analysis, and EBSD}

The investigation of the texture by means of X-Ray Diffraction (XRD) and Electron Backscatter Diffraction (EBSD) was performed on samples oriented transverse to the pressing direction. For XRD measurements, a Bruker D8 Discover with a copper Xray source and an energy dispersive PSD (position sensitive detector) was used. Phase analysis was performed in focusing geometry, while the texture was measured 
in parallel beam geometry. The texture was analyzed using Multex3 (Bruker AXS). The sample preparation for EBSD investigation was performed by the metallographic procedure described above. Additionally, as a finishing step, an ion polishing procedure (JEOL cross section polisher) was used. The EBSD measurements were performed in a Tescan Mira 3 scanning electron microscope using the Norlys-Nano EBSD sensor (Oxford Instruments). The as-received and the heat-treated material were investigated at $20 \mathrm{kV}$ acceleration voltage and a maximum step size of $500 \mathrm{~nm}$. In contrast, the acceleration voltage and the step size had to be decreased to $10 \mathrm{kV}$ and $50-100 \mathrm{~nm}$ for the ECAP-processed samples.

\section{Results}

\section{a. Mechanical properties}

The engineering stress-strain curves of the E675 and AZ31 alloys in the as-received condition under quasi-static tensile loading are shown in Figure 3 . In this case, the strength of $A Z 31$ at $1 \%$ plastic strain $\left(\sigma_{1 \%}\right)$ was approximately $210 \mathrm{MPa}$, the ultimate tensile strength (UTS) was about $280 \mathrm{MPa}$, and the elongation at failure was about $21 \%$. In comparison, the E675 alloy displayed a higher $\sigma_{1 \%}$ of about $380 \mathrm{MPa}$, an UTS of $420 \mathrm{MPa}$, and an elongation at failure of approximately $5 \%$. 


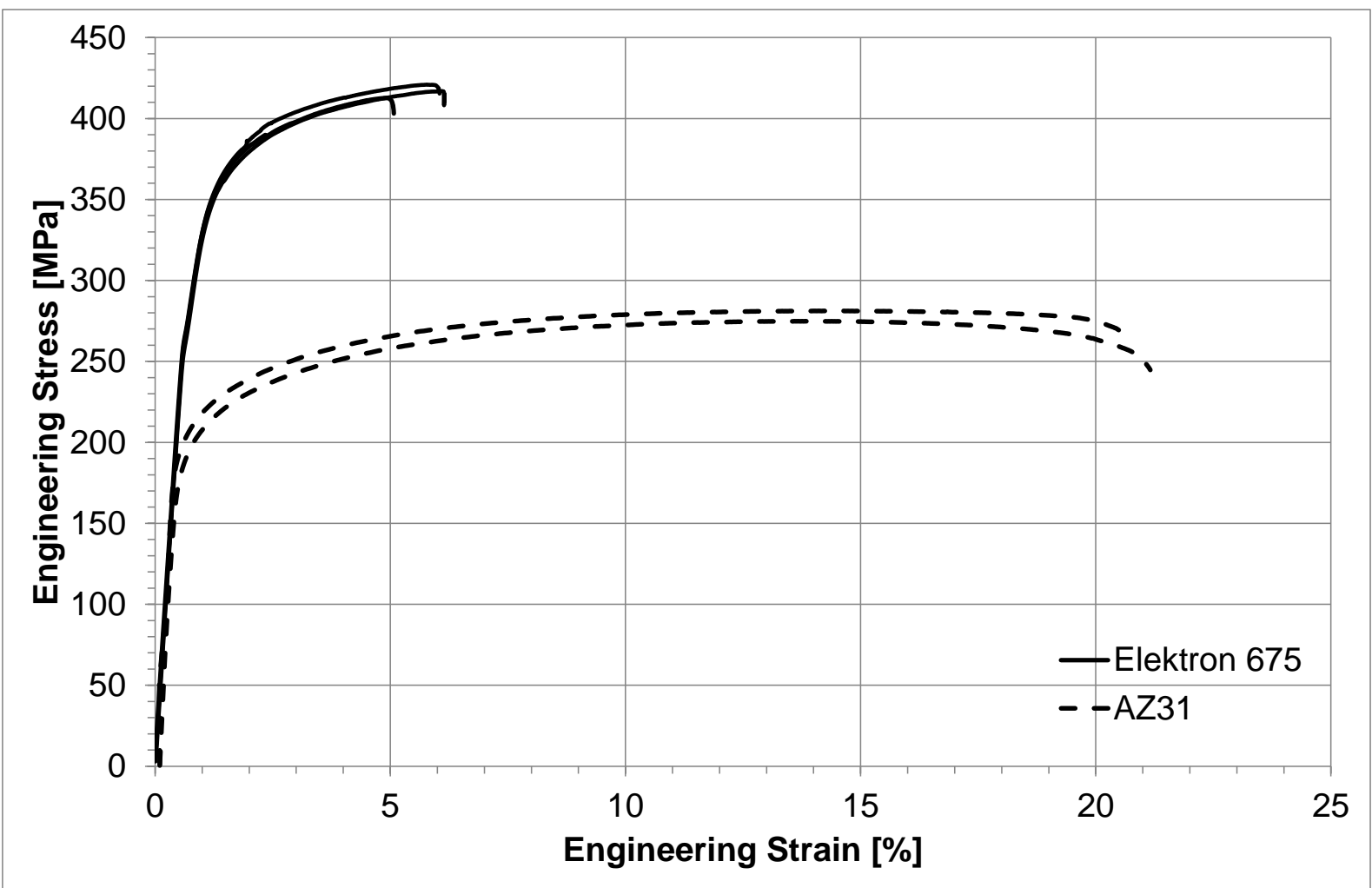

Figure 3: Engineering stress-strain curves of the as-received alloys E675 (solid lines) and AZ31 (dashed lines) under quasi-static tensile loading.

Average engineering stress plastic strain curves for E675 in three different material conditions are shown in Figure 4. Relative to the as-received E675 alloy, ECAP processing for a single pass at $325{ }^{\circ} \mathrm{C}$ resulted in a slight reduction in $\sigma_{1 \%}$ (to $\sim 370$ $\mathrm{MPa}$ ) but a significant improvement in the elongation at failure ( 17\%). After a 45 minute $/ 325^{\circ} \mathrm{C}$ heat treatment, the E675 sample possessed approximately the same elongation at failure as the ECAP processed material. However, $\sigma_{1 \%}$ decreased to about $320 \mathrm{MPa}$ which is nearly $60 \mathrm{MPa}$ lower compared to the ECAP condition. This finding suggests that the increase in the elongation at failure is mainly caused by heat treatment effects, while the enhanced strength observed in the ECAP sample relative to the heat treated sample is due to microstructural changes resulting from the severe plastic deformation. To get more detailed information about the different effects influencing the mechanical properties, the microstructure and texture of different material conditions were subsequently investigated. 


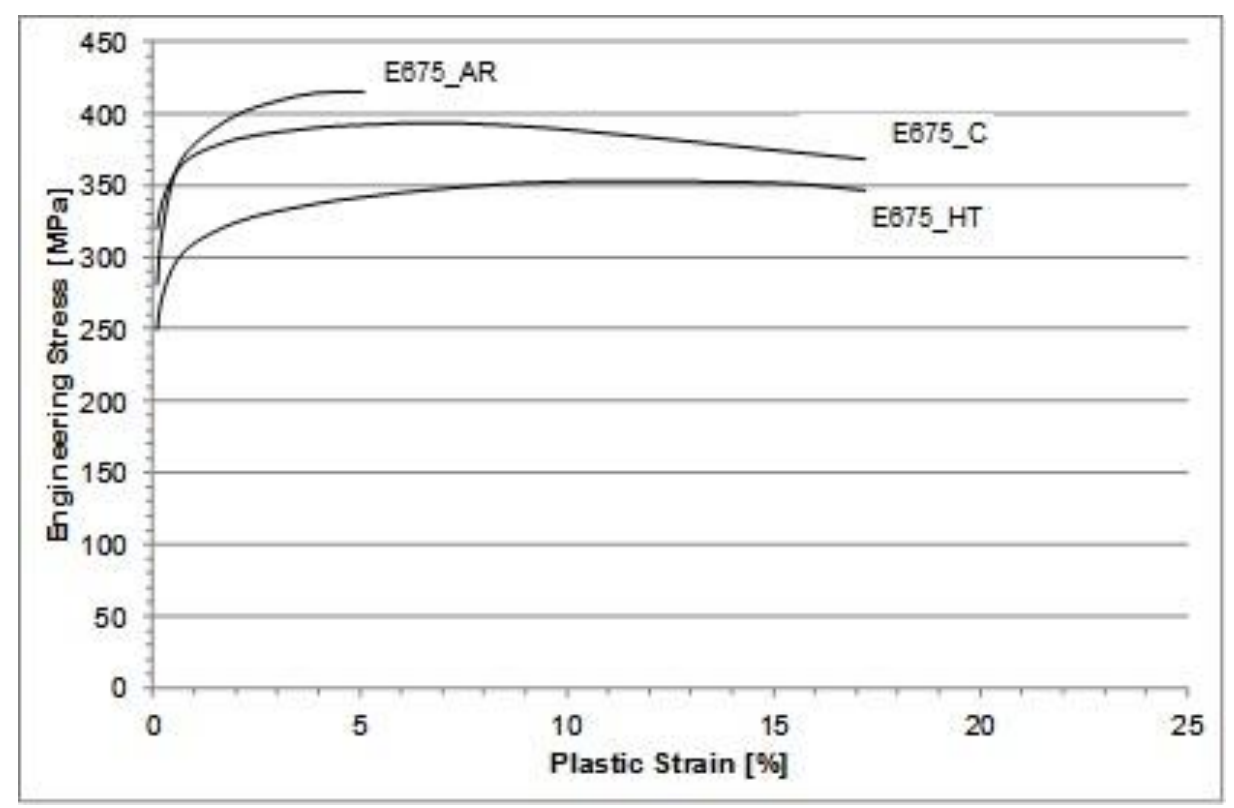

Figure 4: Engineering stress - plastic strain curves for three E675 conditions under quasi-static tensile loading (average flow curves).

The tensile engineering stress-strain curves in quasi-static and dynamic loading for the as-received and ECAP processed (E675_4C) conditions are illustrated in Figures 5 and 6, respectively. Property averages, as well as associated standard deviations, are given in Table 4 as a function of process condition. In the as-received material, a significant increase in $\sigma_{1 \%}$ strength (from $\sim 380 \mathrm{MPa}$ to $440 \mathrm{MPa}$ ) and an improvement in the elongation at failure (from 5\% to 17\%) was observed with increasing strain rate. In contrast, the results for the ECAP processed alloy were mixed. Although the $\sigma_{1 \%}$ strength increased from approximately 345 to $380 \mathrm{MPa}$, the elongation at failure decreased significantly (from 22 to 9\%) with increasing strain rate. The $\sigma_{1 \%}(345 \mathrm{MPa})$ for the ECAP alloy under quasi-static tensile loading conditions is $35 \mathrm{MPa}$ lower than that of the as-received material. More notable, however, is the greater than four-fold increase in the elongation at failure ( $22 \%$ vs $5 \%)$ for the ECAP condition relative to the as-received material. These results can be explained by changes in microstructure (see section b) and by changes in the failure mechanism observed through scanning electron microscopy of respective fracture surfaces (see section c). 


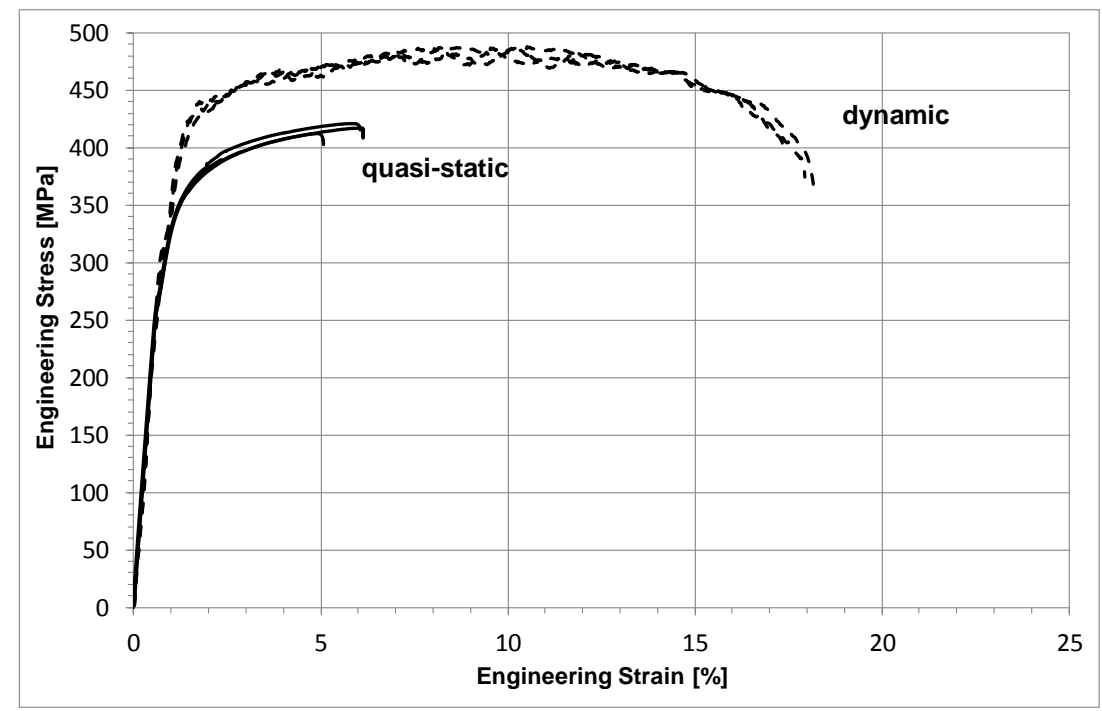

Figure 5: Engineering stress-strain curves of E675_AR for quasi-static and dynamic tensile loading (strain rate: $\sim 1000 \mathrm{~s}^{-1}$ )

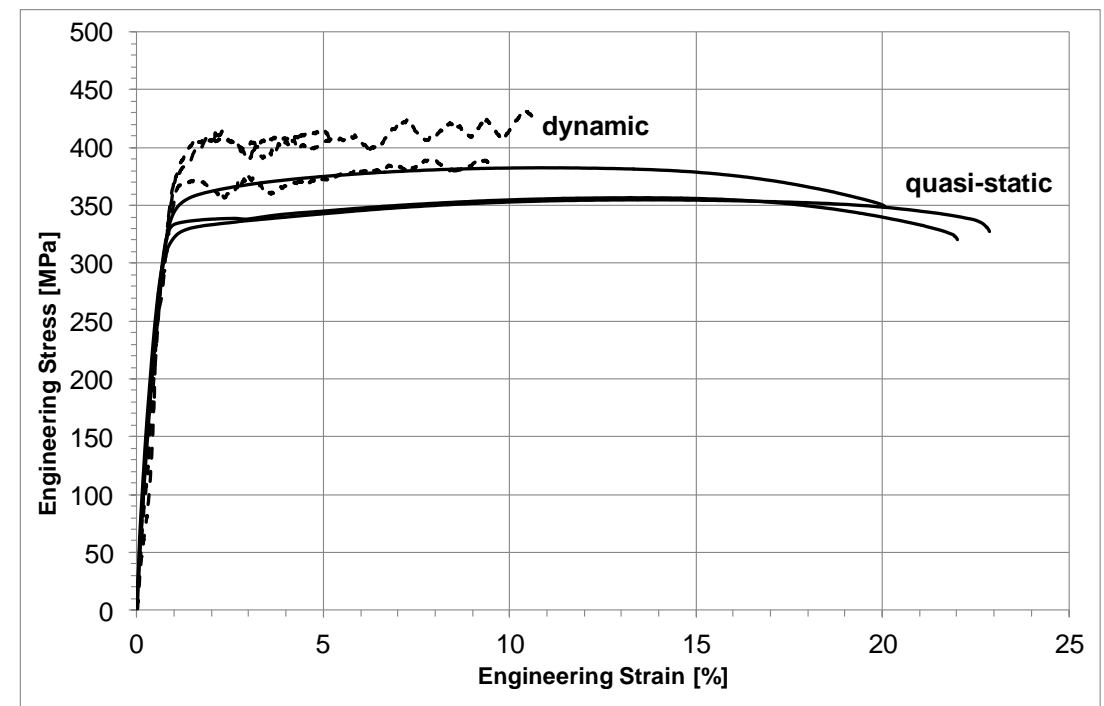

Figure 6: Engineering stress-strain curves for ECAP processed (E675_4C) for quasistatic and dynamic tensile loading (strain rate: $\sim 1000 \mathrm{~s}^{-1}$ ).

Table 4: Quasi-static and dynamic tensile properties for E675 in different conditions.

\begin{tabular}{|c|c|c|c|c|}
\cline { 2 - 5 } \multicolumn{1}{c|}{} & Material & $\sigma_{1 \%}(\mathrm{MPa})$ & UTS $(\mathrm{MPa})$ & Elong. Failure (\%) \\
\hline \multirow{4}{*}{$\begin{array}{c}\text { Quasi- } \\
\text { static }\end{array}$} & E675_AR & $380 \pm 5$ & $420 \pm 5$ & $5 \pm 1$ \\
\cline { 2 - 5 } & E675_HT & $320 \pm 10$ & $355 \pm 5$ & $17 \pm 1$ \\
\cline { 2 - 5 } & E675_C & $370 \pm 15$ & $395 \pm 5$ & $17 \pm 1$ \\
\cline { 2 - 5 } & E675_4C & $345 \pm 15$ & $365 \pm 15$ & $22 \pm 2$ \\
\hline
\end{tabular}




\begin{tabular}{|c|c|c|c|c|}
\hline \multirow{2}{*}{ Dynamic } & E675_AR & $440 \pm 5$ & $480 \pm 5$ & $17 \pm 1$ \\
\cline { 2 - 5 } & E675_4C & $380 \pm 20$ & $400 \pm 15$ & $9 \pm 1$ \\
\hline
\end{tabular}

Finally, the amount of energy absorbed during quasi-static tensile deformation of the different E675 samples is shown in Figure 7. The absorbed energy was calculated by integrating the force-displacement curve from the origin to sample failure. In the asreceived condition, the material has the lowest absorbed energy. After one ECAP pass at $325^{\circ} \mathrm{C}$, the energy reaches a level of about $6 \pm 2 \mathrm{~J}$. The heat-treated material reaches a value slightly less than $6 \mathrm{~J}$, a result which is mainly due to the increased elongation at failure (see Figure 4). The highest absorbed energy $(8 \pm 0.5 \mathrm{~J})$ was observed in the material condition E675_4C. Compared to the as-received material, this material displayed a fourfold increase in absorbed energy.

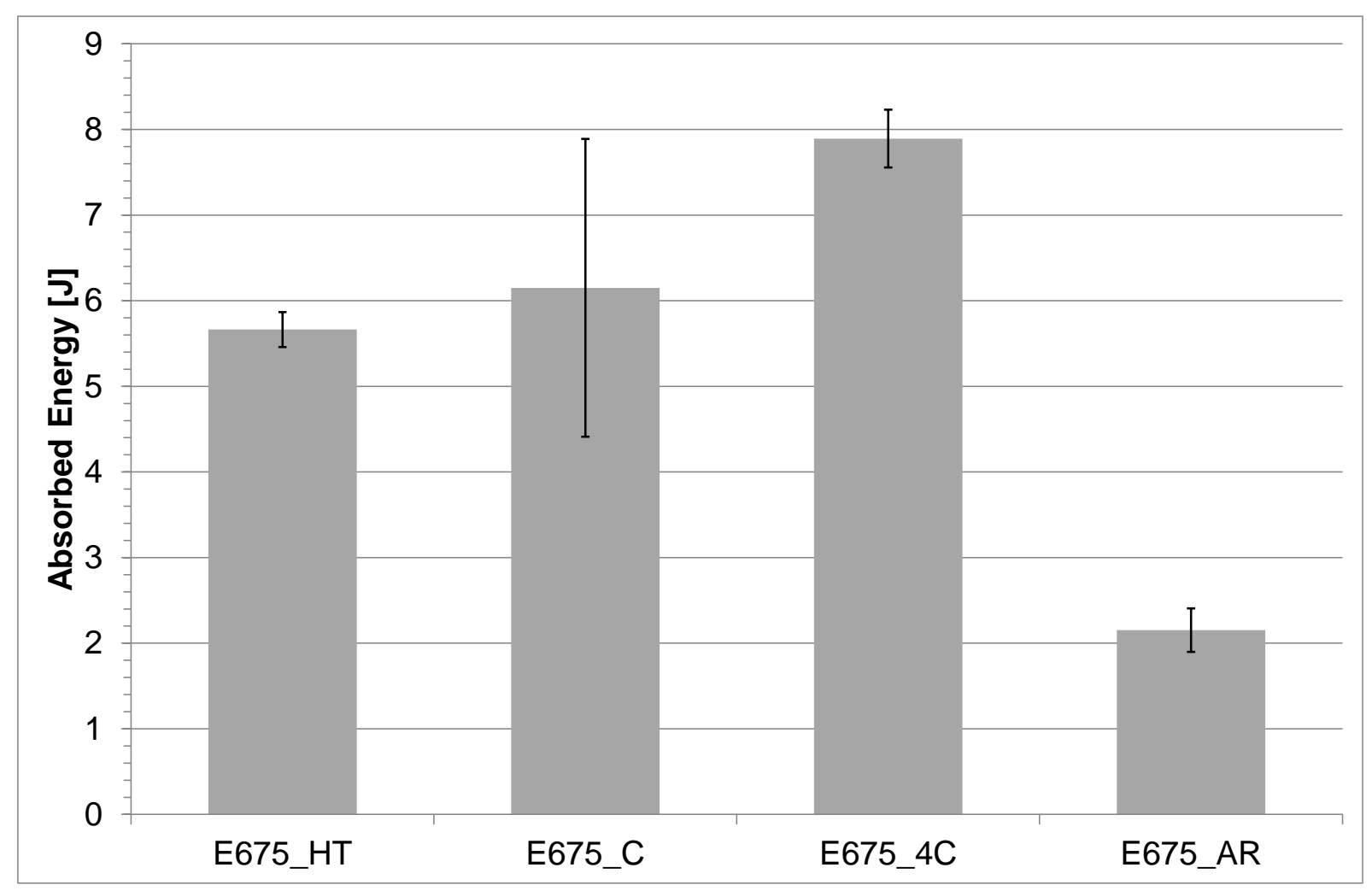

Figure 7: Comparison of the absorbed energy under quasi-static tensile loading. 


\section{b. Microstructure and Texture}

The microstructure of the E675 alloys in the as-received condition and after ECAP

(E675_4C) is shown in

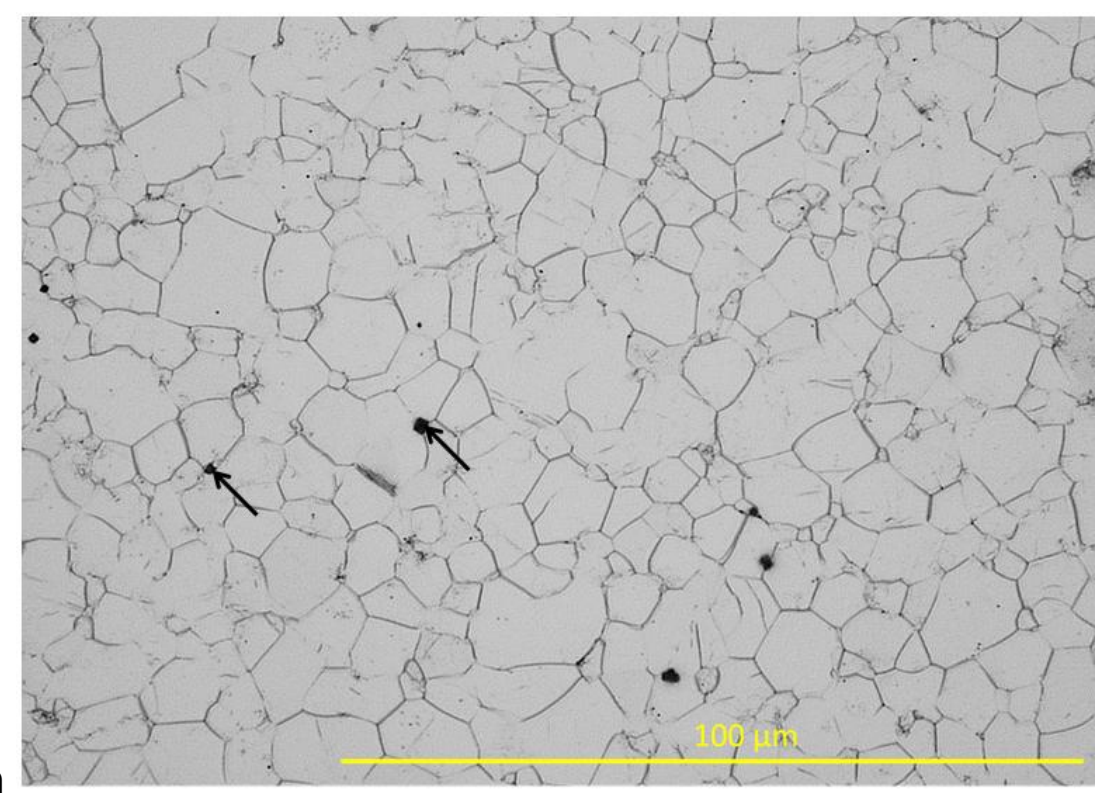

Figure 8 and 9, respectively. In the as-received condition, the average grain size is about $6 \mu \mathrm{m}$. In addition, small cubic precipitates mainly located at the grain boundaries were observed. After ECAP processing, the grain sizes are changed into a strong bimodal configuration. As seen in Figure 9, larger grains are surrounded by numerous smaller grains with a size less than $1 \mu \mathrm{m}$. This effect is typical for $\mathrm{Mg}$ alloys with higher amounts of rare earth elements and was also observed by Zhang et al. [16]. Furthermore, the microstructure is characterized by small cubic precipitates (full lined arrows) along with a second type of spherical precipitates formed by ECAP processing (see dashed line arrows in Figure 9). Using Energy Dispersive X-Ray Spectroscopy (EDX), Zhang et al. determined that the cubic phase is rich in $\mathrm{Gd}$ and $Y$ while the spherical phase is rich in $\mathrm{Zr}$ [16]. The results of Differential Scanning Calorimetry (DSC) experiments indicated that at a temperature of about $300{ }^{\circ} \mathrm{C}$, a broad peak (80 ${ }^{\circ} \mathrm{C}$ width) occurs which is associated with the formation of a second phase (see Figure 10). The chemical composition and the lattice type are discussed in the next section. 


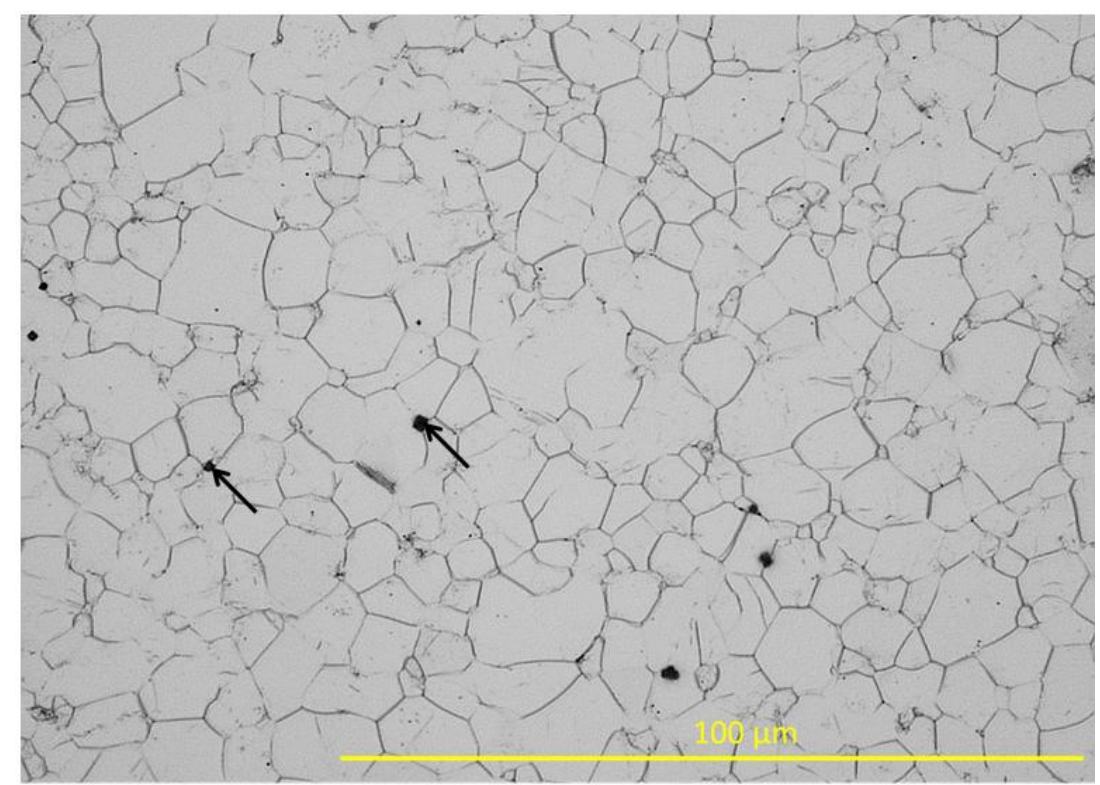

Figure 8: Optical Micrograph of the Microstructure of E675_AR (transverse).

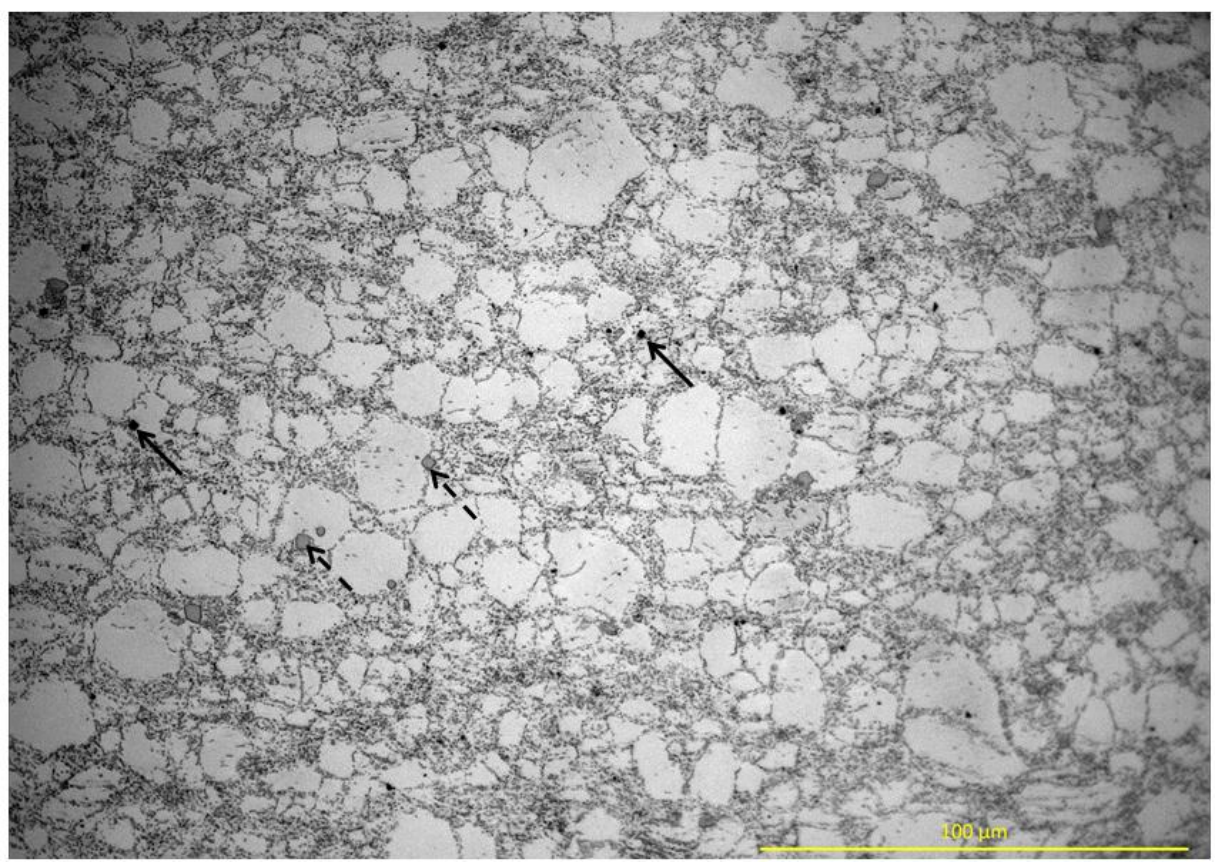

Figure 9: Optical Micrograph of the Microstructure of E675_4C (transverse). 


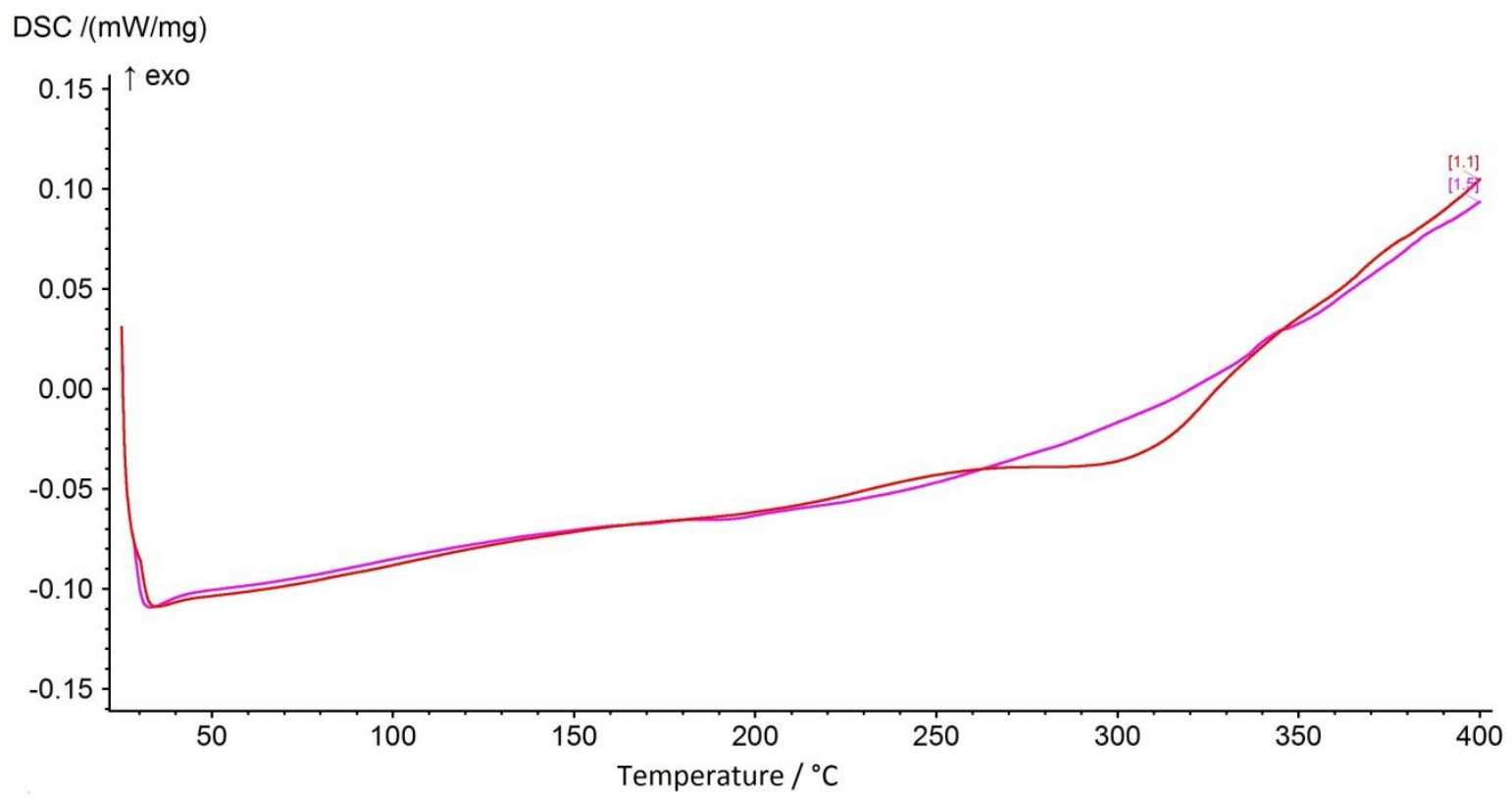

Figure 10: DSC trace obtained from the E675 alloy heated up to $400{ }^{\circ} \mathrm{C}$. The red curve was obtained on heating, while the pink curve was obtained on cooling of the sample.

The longitudinal microstructure of the material in the as-received condition was characterized by EBSD (Figure 11). As the alloy was received in the extruded condition, a band-like formation of grains can be observed in which the small grains (2-3 $\mu \mathrm{m})$ are oriented chain-like between the larger grains (approximately $30 \mu \mathrm{m}$ ). This band-like formation is still present even after heat treatment ( $325^{\circ} \mathrm{C} / 45$ minutes) of the as-received material (Figure 12). In contrast, ECAP processing (E675_4C) resulted in the formation of a more refined microstructure (grain size of about $1 \mu \mathrm{m}$ ), although some larger grains are still present (Figure 13). 


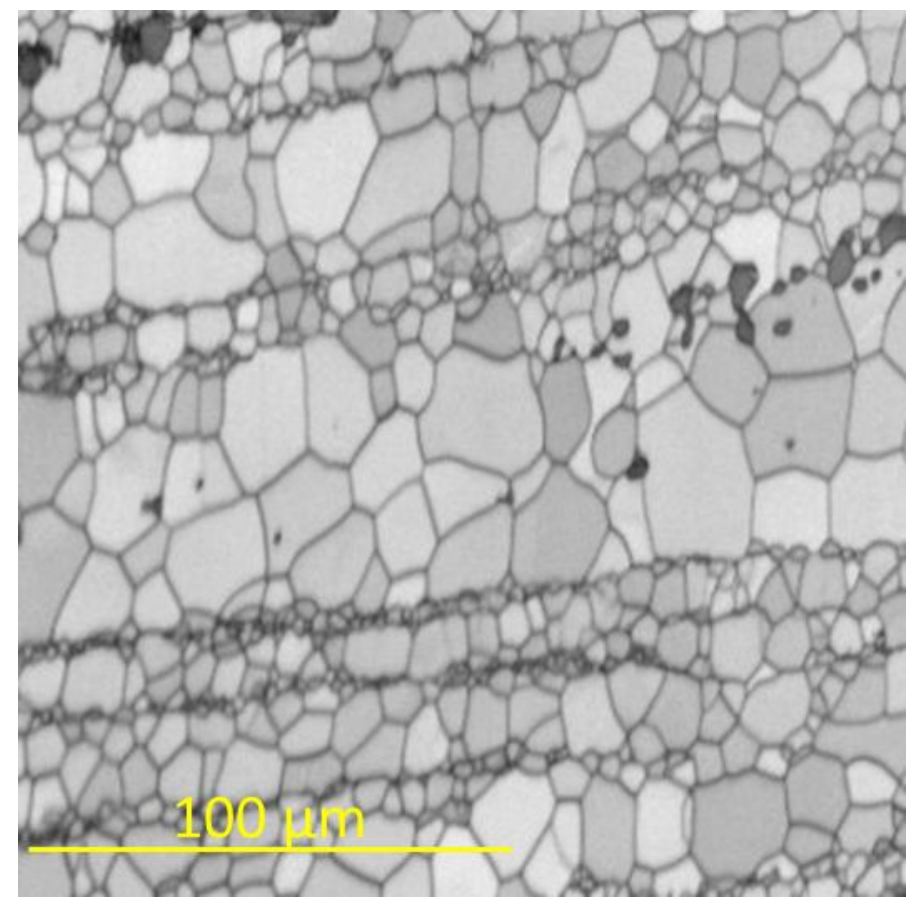

Figure 10: EBSD-band contrast image of E675_AR (longitudinal). Dark areas correspond to low and bright areas to high band contrast values.

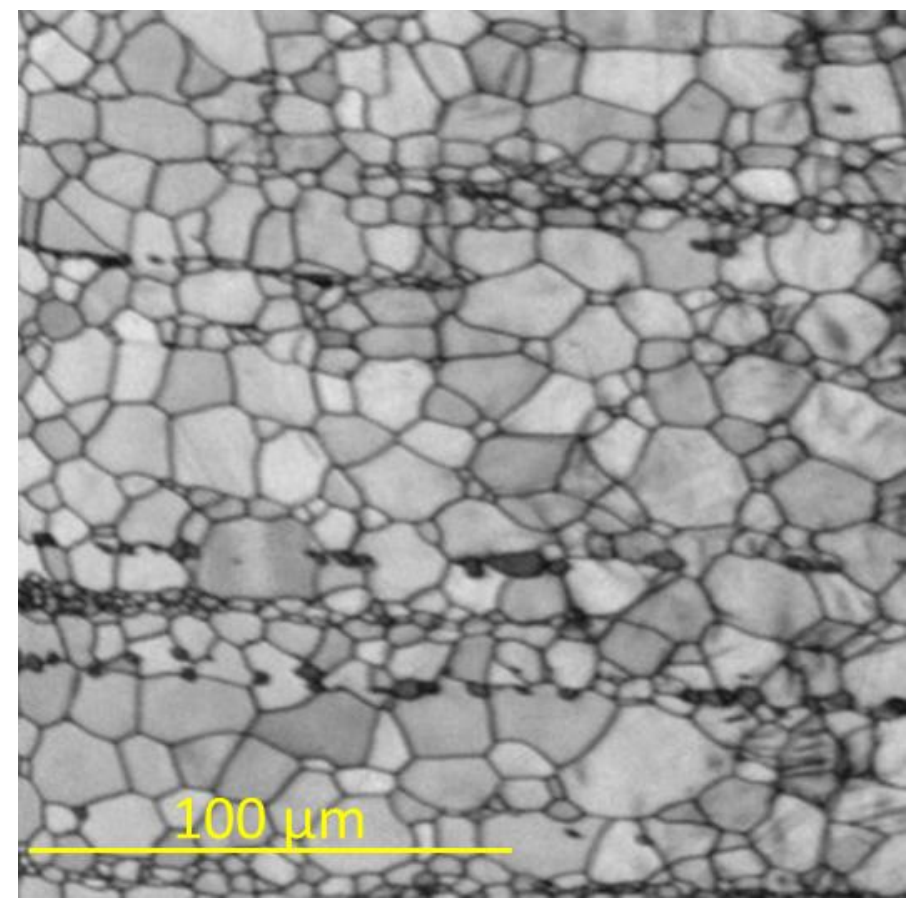

Figure 11: EBSD-band contrast image of E675_HT (longitudinal). Dark areas correspond to low and bright areas to high band contrast values. 


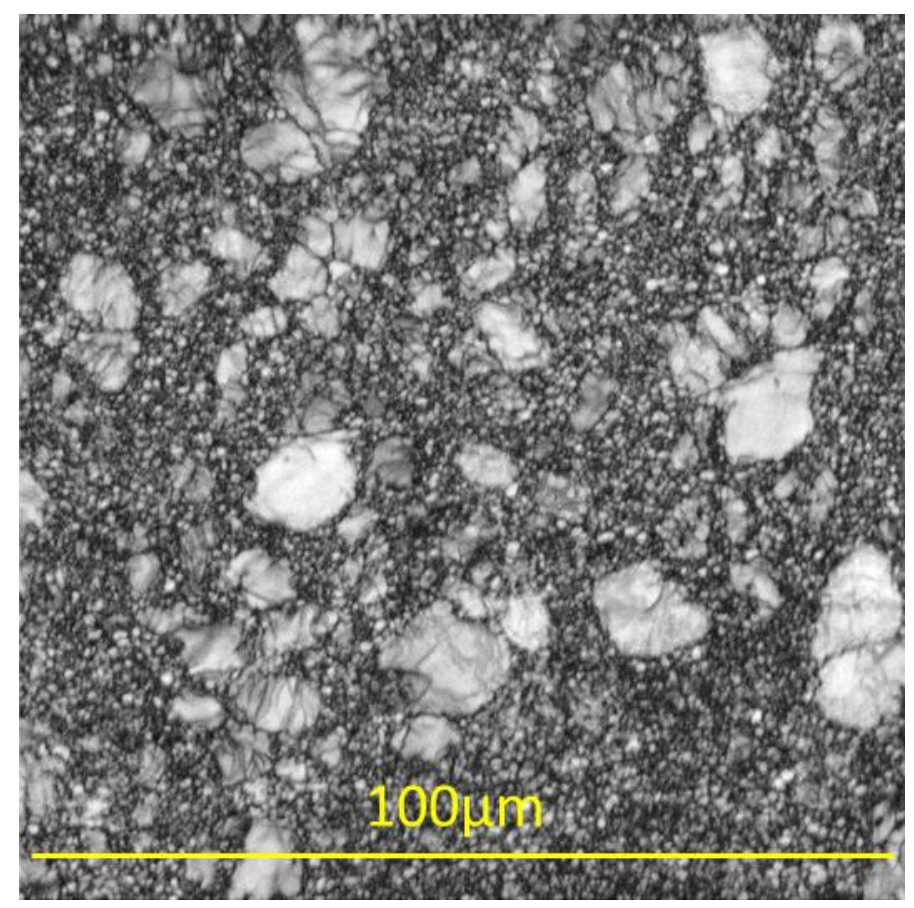

Figure 123: EBSD-band contrast image of E675_4C (longitudinal). Dark areas correspond to low and bright areas to high band contrast values.

\section{Phase analysis}

The diffraction pattern for the as-received, heat treated, and ECAP processed material are shown in Figure 14. As the samples processed by ECAP showed no significant difference in their respective XRD patterns, only the pattern for E675_C alloy is shown. The as-received material displays pure Mg peaks that are slightly broadened with a full width at half maximum of $2 \theta(F W H M)=0.45^{\circ}$ at $2 \theta=34.365^{\circ}$. This broadening is caused by a distortion of the lattice parameters resulting from the presence of the solid solution alloying elements. Although small precipitates were observed in the as-received material, they do not appear in the XRD data. This fact is likely due to their overall small volume fraction.

After heat treatment, the XRD peaks are narrowed and additional peaks are observed. This result can be explained by precipitation which in turn leads to a smaller amount of alloying elements in the Mg-phase. The additional peaks can be associated with a MgY, a MgGd, or, more likely, a MgYGd mixed phase. This interpretation is confirmed by the microstructural investigations and the EBSD band contrast picture, in which additional precipitates enriched with both $\mathrm{Gd}$ and $\mathrm{Y}$ were observed. Due to the segregation of the alloying elements, the $\mathrm{Mg}$ phase becomes more pure, resulting in a reduction of full width at half maximum of the XRD peaks. 
After ECAP processing, the additional peaks are still present but the primary $\mathrm{Mg}$ peaks become broader than the corresponding peaks in the purely heat-treated state. This is due to a reduction of crystallite sizes resulting from the ECAP process. The smaller recrystallized grains $(\sim 0.5-2 \mu \mathrm{m})$ in the necklace-like structures and the larger deformed grains can be directly observed in the EBSD band contrast picture (see Figure 13). Furthermore, it was found by EDX that the $Y$ content in the necklacelike structures is increased in comparison to the larger grains. However, it should be noted that due to the low atomic weight of $\mathrm{Mg}$, the small grain sizes, the large deformation of the material, and the existence of $\mathrm{Y}-\mathrm{Gd}-\mathrm{Mg}$ mixing gradients, the rate of indexing was low (approx. $<50 \%$, corresponding pictures are not shown here) and thus it was not possible to determine the grain size quantitatively by EBSD. However, the amount of precipitates is constant based upon a comparison to the heat treated state.

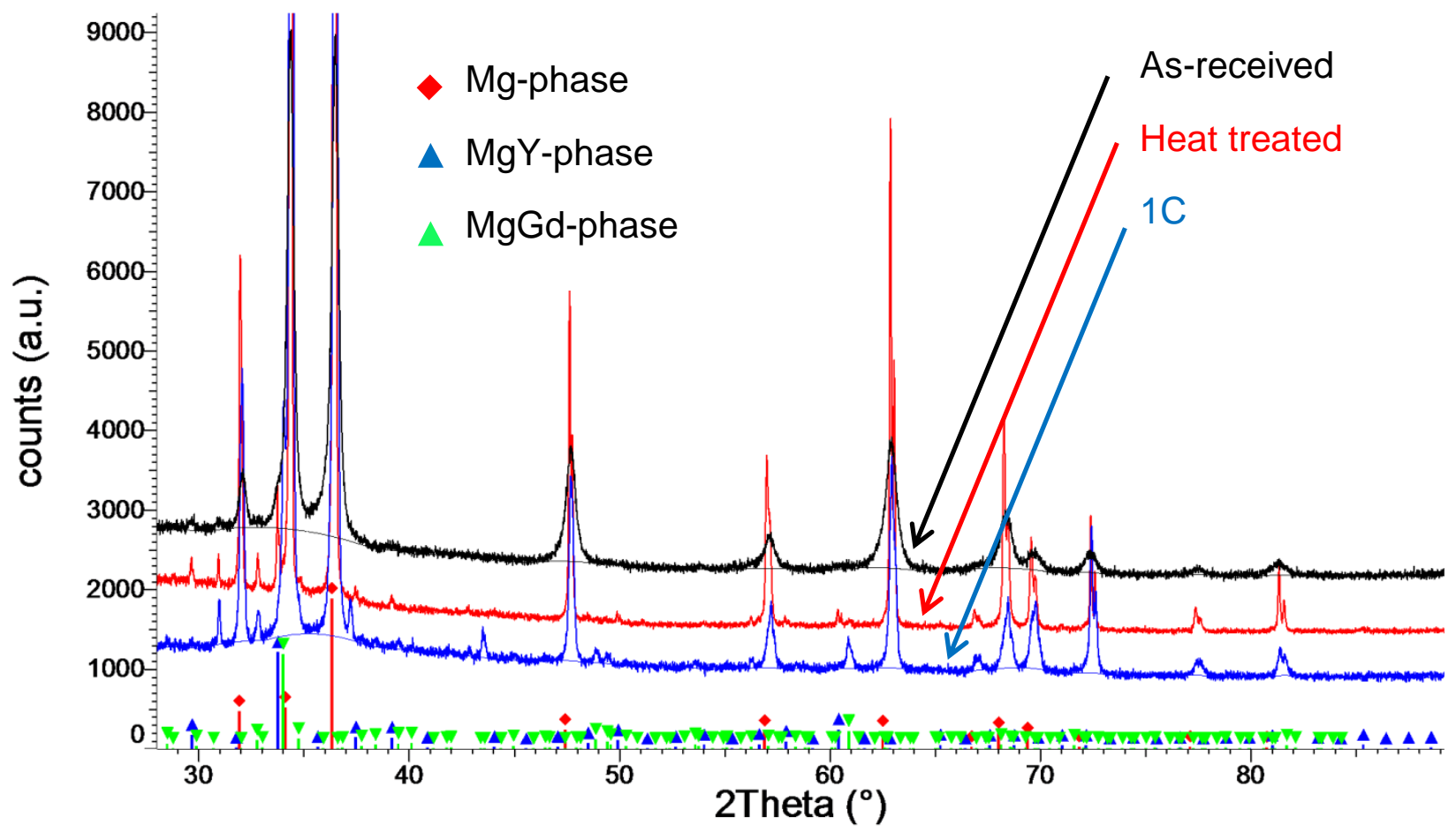

Figure 13: XRD diffraction pattern of E675 as-received (black), heat treated (red) and 1C (blue) (shifted along the ordinate for clarity). Theoretical peaks of a pure Mgphase (red diamonds), MgY-phase (blue triangles) and MgGd-phase (green reversed triangles) are indicated on the bottom.

\section{Texture}

The pole figures (0002 peak) of the as-received and ECAP processed samples are shown in Figure 15. As expected, the texture of the as-received material corresponds 
to that of an extruded material. The texture of the annealed sample (not shown) did not differ significantly from the as-received material. In contrast, one ECAP pass changed the texture such that it was primarily a single pole corresponding to the 0002 peak. Further passes (e.g., E675_4C) resulted in the pole being inclined by $45^{\circ}$ to the extrusion axis.
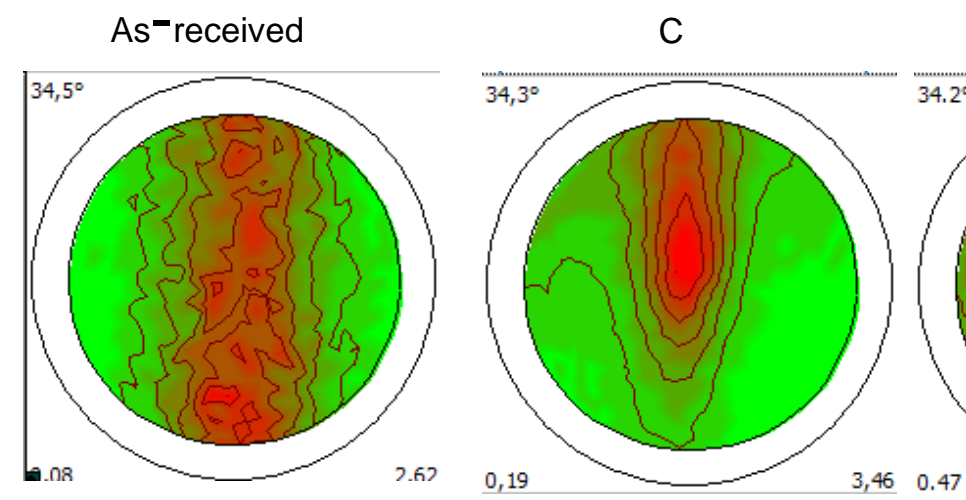

$4 \mathrm{C}$

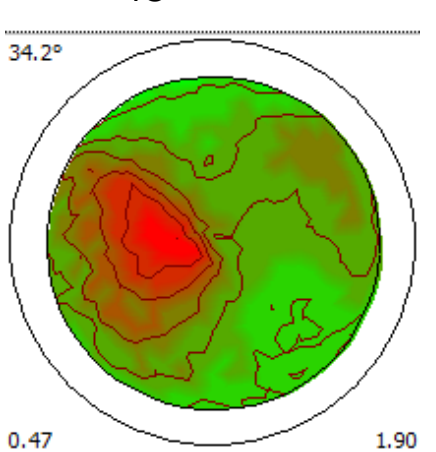

Figure 14: Pole figure of the 0002 peak of E675 as received (left), E675_C (center), and E675_4C (right).

\section{c. Examination of the fracture surface}

An overview of the fracture surfaces of all samples after quasi-static tensile testing is shown in Figure 16. Despite the fact that ductile characteristics are found in all samples, significant differences exist. For the samples in the as-received state, cleavage planes and honeycomb-like structures are found in the secondary electron (SE) image (Figure 16a). These examinations clearly point to a ductile failure mechanism in the material. In the backscattered electron (BE) picture, only a small amount of fine Gd- or Y- rich precipitates are found (bright areas in Figure 16b) 
In comparison to the as-received state, the fraction of cleavage planes is increased in the heat treated state (Figure 16c). In addition, some crack-like structures perpendicular to the fracture surface are observed. The BE picture (Figure 16d) shows a significant increase in the amount of Gd-/Y-rich precipitates (bright areas) approximately $0.5-5 \mu \mathrm{m}$ in size. The majority of the larger precipitates have been cleaved. In addition, the occurrence of interfacial cracking between the matrix and precipitates is quite noticeable. It is likely that the increase in ductility results from the hindrance of crack propagation by these precipitates.

In contrast to the as-received or the heat treated sample, the fracture characteristics of the E675_4C sample is much finer (Figure 16e). The typical size of the honeycomb-like structures is on the order of $0.5 \mu \mathrm{m}$ (Figure 17a). These features are the most prominent fracture marks on the surface, as almost no cleavage planes or other crack-like structures are found. However, the most remarkable difference is found in the BE picture (Figure 16f). Whereas larger precipitates are infrequently seen, smaller precipitates are homogenously distributed over the whole area (small bright spots in Figure 16f) of the fracture surface. The size of the smaller precipitates is on the order of a few hundred nanometers (bright areas in Figure 17b). These precipitates correspond to the Y-rich precipitates found in the necklace-structures surrounding the larger grains. The finding that these precipitates are homogenously distributed over the entire fracture surface in combination with the small typical size of the honeycomb-like fracture structures points to the fact that the failure mechanism propagates mainly within the necklace-like structures. The increase in strength of the E675_4C alloy relative to the heat-treated material can therefore be attributed to grain boundary and precipitation strengthening. The simultaneous increase of the ductility is probably a consequence of crack propagation disturbance by the larger grains still present in the microstructure. 

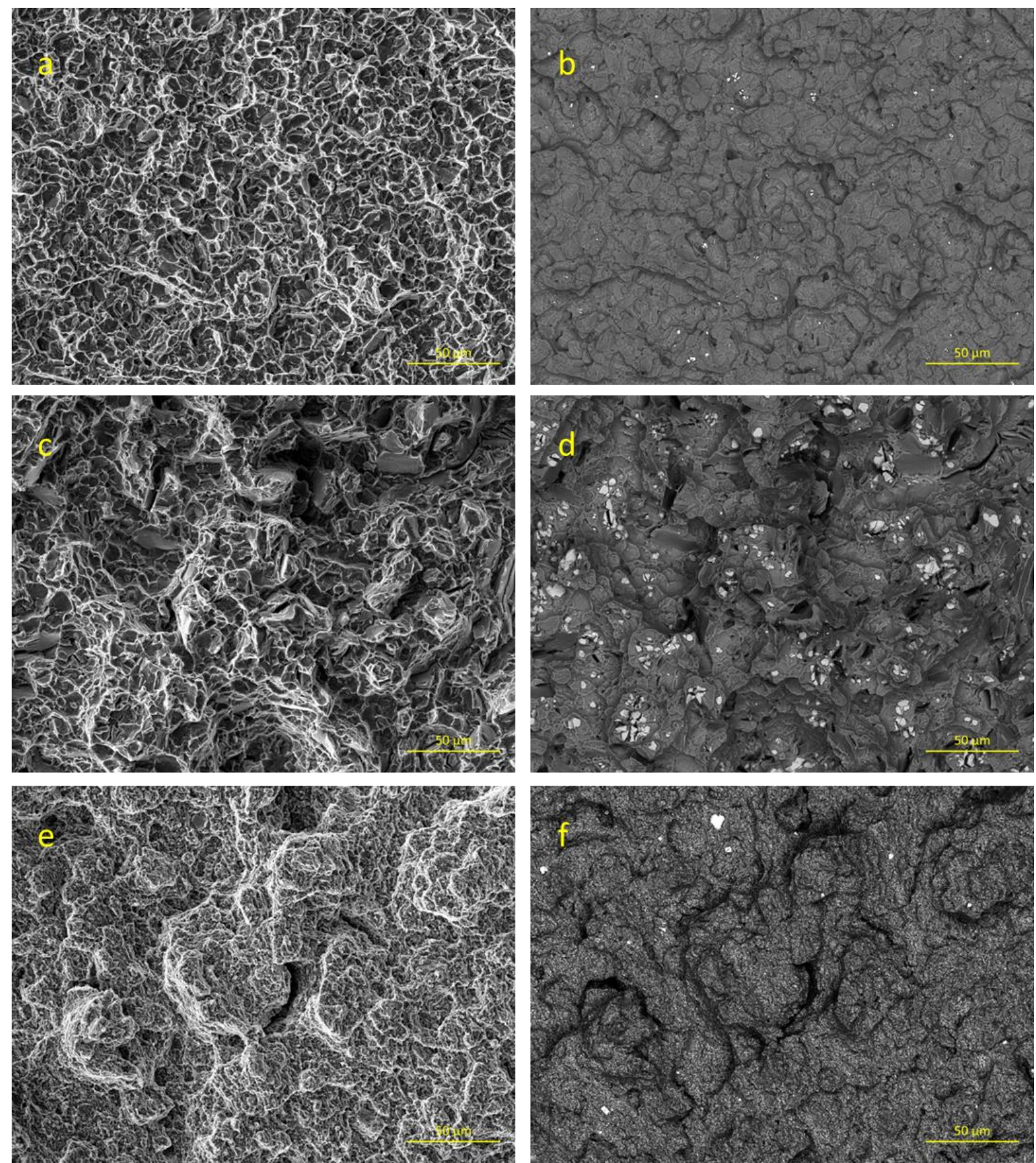

Figure 16: Fracture surfaces of the samples after quasi static tensile test. (a) The secondary electron (SE) picture of the sample in the as received state, (b) the backscattered electron (BE) picture of the area shown in (a), (c) SE picture of the sample in the heat treated state, (d) BE picture of the area shown in (c), (e) SE picture of the E675_4C sample, (f) BE picture of the area shown in (e). 

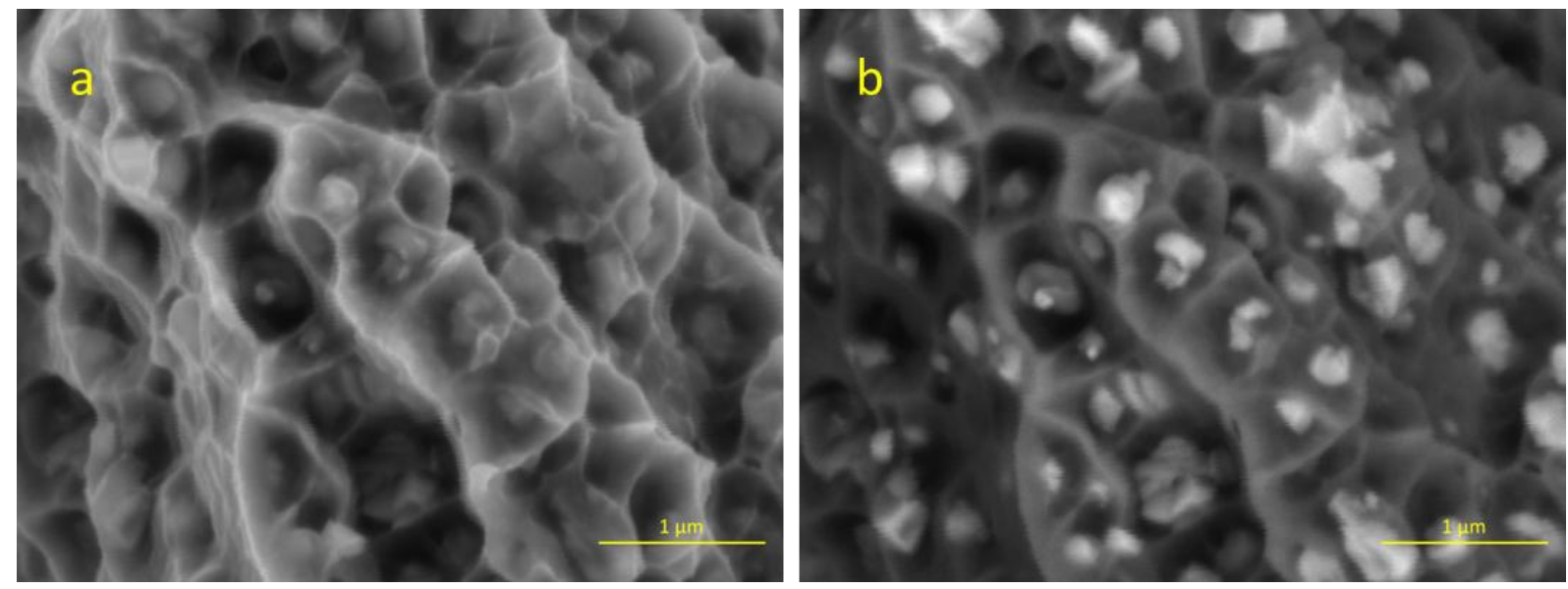

Figure 15: (a) Ultrahigh magnification SE picture of the fracture surface of the E675_4C sample and (b) the BE picture of the same area shown in (a).

\section{Discussion}

The ability of ECAP to produce highly refined microstructures in a "simple" (or solid solution strengthened) Mg alloy such as AZ31 has been well documented in the literature. However, it is still uncertain as to whether ECAP can achieve such levels of grain refinement and property enhancement in precipitation strengthened alloys such as E675. Indeed, studies on another precipitation strengthened alloy, namely ZK60, have indicated that a bimodal grain structure still exists even after multiple ECAP passes at temperatures over $240{ }^{\circ} \mathrm{C}$ [22-24]. Results observed in ECAP ZK60 alloys have typically been mixed, with an improvement in ductility offset by a marginal improvement, if not a reduction, in strength values [24]. It was with these observations in mind that the ECAP routes selected for this study ranged from a simple one pass method to a four step temperature step down method in an attempt to gain insight into which approach may prove most beneficial in regards to E675.

Before addressing the results for the ECAP samples, it is first necessary to examine the influence of a simple thermal annealing treatment on the alloy. Comparison to the as-received alloy indicated that annealing resulted in an approximate 15\% reduction in yield strength. Although microstructural examination revealed the formation of fine $\mathrm{Mg}\left(\mathrm{Y}, \mathrm{Gd}\right.$ ) precipitates (perhaps $\mathrm{Mg}_{5}(\mathrm{GdY})$ ) [23], the low volume fraction of these precipitates suggests that they are unlikely to offer much strengthening to the alloy after annealing. As a result, the strength of the alloy decreased by approximately 60 $\mathrm{MPa}$. In contrast, the ductility increased by over four times. However, as seen in earlier studies $[25,26]$, the texture of the alloy was not noticeably changed. Thus, the 
significant improvement in ductility is attributed to annealing induced changes as well as the potential hindrance of crack propagation due to the presence of precipitates.

The first ECAP route, 1 pass at $325^{\circ} \mathrm{C}$, resulted in a minimal $(10 \mathrm{MPa})$ reduction in yield strength relative to the as-received alloy. In contrast, the ductility of the sample was dramatically increased. This combination of property changes has been observed in a broad range of $\mathrm{Mg}$ alloys [16, 24, 26]. In work on a similar alloy, Mg11.9Gd-0.81Y-0.44Zr, this behavior was attributed to textural changes that occurred after a single ECAP pass that resulted in a more favorable grain orientation that could better accommodate the imposed tensile strain [16]. Indeed, in work on AZ31, it was noted that orientation of the basal plan such that it was the favored deformation mode would result in a lower yield stress accompanied by enhanced ductility [26]. Texture measurements conducted on the sample support this observation of preferred orientation.

With the use of the temperature step-down ECAP (E675_4C) method, significant changes in microstructural features were observed. Of these, perhaps the most notable is that texture measurements indicated that the 0002 peak was now inclined approximately $45^{\circ}$ to the extrusion axis (which in this case is also the tensile loading axis). Such an orientation may explain the further combination of reduced strength and increased ductility in the alloy, as Agnew et al [25] have shown that this is a soft orientation in Mg alloys, resulting in a higher ductility. These observations are in good agreement with work on extruded AZ61 that determined the most favorable orientation for slip on the basal plane occurred when the c-axes were tilted at approximately $57^{\circ}$ to the tensile direction [27]. Finally, the bimodal grain size distribution, as characterized by larger grains surrounded by smaller $(<1 \mu \mathrm{m})$ grains, is also known to contribute to improved ductility [28].

However, for E675_4C the improvement in ductility is somewhat offset by a slight reduction in strength relative to the as-received and one ECAP pass alloys. This observation is attributed to the change in texture, such that the alloy is in a soft orientation for slip [25]. In effect, the texture of the alloy is the primary feature determining the mechanical properties, as it "over-rides" any strength increase resulting from grain size refinement or precipitate formation. A similar observation was made on ZK60 alloy processed using either a 4 or 8 pass temperature step down ECAP method [23]. For the case of the 4 pass sample, there was an 
appreciable loss in strength relative to the as-received alloy despite having a finer grain size, as the texture had shifted to approximately $45^{\circ}$ to the extrusion (tensile) direction. It was only when an additional 4 passes were performed, resulting in the same texture but an even finer grain size, that the strength of the alloy was appreciably increased. Thus, it is possible that the strength of the E675 alloy could be better enhanced if an 8 step ECAP method had been used. Alternatively, it is also possible that the use of back-pressure during the ECAP process may also yield further improvements in properties, as its use has been shown to enhance grain size reduction and inhibit crack formation during processing [29].

Similar to earlier work on WE43 [30, 31] and AZ31 [32], an appreciable increase in strength was observed for both the as-received and ECAP processed E675 when tested under dynamic conditions. For the case of the as-received material with a strong basal texture, it is probable that prismatic and basal slip are predominant in the response of the material [32]. However, textural changes in the ECAP alloy have likely resulted in a more complex deformation response. Despite this difference, however, it is likely that the observed strength increase is due to the strain rate dependence of non-basal slip, as it has been shown that the critical resolved shear stress of basal slip is independent of strain rate [33]. An additional phenomenon that may help to explain the higher strength was proposed by Suyuan following dynamic testing of AZ31 [34]. After noting that the compressive strength progressively increased with increasing strain rate, he theorized that thermally activated dislocation movement at high strain rates is replaced by dislocation drag effects, thereby leading to a significant increase in strength.

Finally, in contrast to the strength increase observed in both alloys, only the ductility of the as-received alloy was observed to increase under dynamic conditions. Typically, the increased ductility of metallic materials under high strain rates is explained by adiabatic effects. The temperature increase under adiabatic conditions can be calculated by [35]

$$
\Delta T=\frac{\eta}{\rho c_{p}} \int \sigma(\varepsilon) d \varepsilon_{p}
$$

where $\quad \Delta T \quad \ldots \quad$ increase of temperature

$\eta \quad \ldots \quad$ ratio of deformation energy which is transformed into heat (for pure adiabatic condition $\eta=1$ )

$\rho \quad \cdots \quad$ density $\left(\rho=1.95 \mathrm{~g} / \mathrm{cm}^{3}\right)$ 
magnesium).

Substitution of the appropriate values into equation 1 results in a temperature increase of approximately $40 \mathrm{~K}$. This temperature increase is not sufficient to activate non-basal slip planes in the hcp lattice. Thus, adiabatic effects cannot account for the increase in ductility with increasing strain rate seen in the as-received alloy.

Another possible explanation for the ductility increase in the E675_AR samples was proposed by Mukai et al. [30] following their study on an extruded WE43 alloy in which a large increase in ductility with increasing strain rate was observed. By analyzing the fracture surface, an intergranular fracture was observed under quasistatic loading conditions and a transcrystalline fracture at dynamic strain rates. As a result, it was theorized that the change of fracture type might be caused by the fine grain size $(\sim 1.5 \mu \mathrm{m})$ of WE43. However, this explanation seems questionable in view of the large ductility reduction observed in the E675_4C alloy, which had a much finer grain size than the as-received alloy. Indeed, microstructural examinations conducted during this study did not reveal any changes in fracture mode of the as-received and ECAP processed E675 alloys due to the different strain rates.

Although more microstructural studies are needed to identify the cause of the ductility response observed in the two E675 alloys, it has been observed that deformation twinning increases with increasing strain rate when the basal planes are oriented parallel to the loading direction in AZ31B [36] as well as many other metals [37]. Such an observation may explain the increase in the E675_AR alloy, as this alignment is nominally the case for the testing of this alloy. In contrast, the non-basal texture of the ECAP alloy, in combination with its bimodal microstructure, may account for the significant decrease in failure elongation observed under dynamic conditions.

\section{Summary and Conclusions}

The microstructural and mechanical properties of Electron 675 in the as-received state and after different ECAP routes were studied under both quasi-static and dynamic strain rates. Microstructural examination after a four-step, temperature stepdown ECAP process indicated that the layered grain structure of the as-received 
alloy had been replaced with an appreciably refined microstructure, although some larger grains remained. Mechanical testing indicated that the as-received alloy had the highest strengths relative to a thermally annealed or ECAP processed samples. Indeed, the E674_4C sample had a lower strength than a one-pass ECAP sample, a result likely due to the observed textural changes in this sample. Despite the lower strength, the E675_4C alloy was found to have the highest level of absorbed energy under quasi-static tensile loading due its much improved ductility. Dynamic testing revealed a strength increase for both the as-received and 4C ECAP alloy, although the ductility of the latter was found to be reduced.

In closing, this study has indicated that an ECAP processing method utilizing a temperature stepdown method can achieve significant microstructural refinement and accompanying mechanical property enhancement in a complex magnesium alloy. However, the results obtained indicate that the four step recipe used in this effort is not sufficient to achieve a simultaneous increase in both strength and ductility. Thus, future efforts should focus on the development of a more complex recipe, either in the number of steps or temperature profile, that will yield the desired property enhancements.

\section{Acknowledgments}

The authors would like to thank G. Nolze (BAM Berlin), F. Bauer (Oxford Instruments), S. Mücklich (Westsächsiche Hochschule Zwickau), C. Gläser and K. Muhr (Technische Universität Chemnitz) for the fruitful discussions.

In addition, one of the authors ( $\mathrm{VHH}$ ) would like to acknowledge funding received from the Office of the Deputy Assistant Secretary for Defense Exports and Cooperation (DASA (DE\&C)) that enabled his appointment to WIWeB as part of the U.S. Department of Defense Engineer and Scientist Exchange Program. 


\section{References}

[1] $\quad H$. Yoshinaga and R. Horiuchi, "Deformation mechanisms in magnesium single crystals compressed in direction parallel to hexagonal axis," Trans. JIM 4 (1963) 1-8.

[2] D. Wu, R.S. Chen and E.H. Han, "Excellent room-temperature ductility and formability of Mg-Gd-Zn alloy sheets," J. Alloys and Compounds 509 (2011) 28562863.

[3] Y. Gao, Q. Wang, G. Jinhai, Y. Zhao, Y. Tong and J. Kaneda, "Effects of heat treatments on microstructure and mechanical properties of Mg-15Gd-5Y-0.5Zr alloy," J. Rare Earths 26 (2008) 298-302.

[4] L. Gao, R.S. Chen and E.H. Han, "Microstructure and strengthening mechanisms of a cast Mg-1.48Gd-1.13Y-0.16Zr (at.\%) alloy," J. Materials Science 44 (2009) 4443-4454.

[5] G. Yongchun, L. Jianping, L. Jinshan, Y. Zhong, Z. Juan, X. Feng and L. Minxian, "Mg-Gd-Y system phase diagram calculation and experimental clarification," J. Alloys and Compounds 450 (2008) 446-451.

[6] B. Smola, I. Stulikova, F. von Buch and B.L. Mordike, "Structural aspects of high performance Mg alloys design," Materials Science and Engineering A 324 (2002) 113-117.

[7] L. Gao, R.-S. Chen and E.-H. Han, "Fracture behavior of high strength Mg-GdY-Zr magnesium alloy," Trans. Nonferrous Met. Soc. China 20 (2010) 1217-1221.

[8] S. Sandlöbes, S. Zaefferer, I. Schestakow, S. Yi and R. Gonzales-Martinez, "On the role of non-basal deformation mechanisms for the ductility of $\mathrm{Mg}$ and $\mathrm{Mg}-\mathrm{Y}$ alloys," Acta Materialia 59 (2011) 429-439.

[9] Elektron 675 Preliminary Data, Magnesium Elektron UK, 2010.

[10] P. Hazel, G.J. Appleby-Thomas, E. Wielewski, C.R. Siviour and C. Stennet, "On the shock response of the magnesium alloy Elektron 675," AIP Conf. Proc., vol. 1426 (2012) 983-986.

[11] T. Jones and B. Placzankis, "The ballistic and corrosion evaluation of Magnesium Elektron E675 vs. baseline magnesium alloy AZ31B and aluminum alloy 
5083 for armor applications," United States Army Research Laboratory (ARL-TR5565), 2011.

[12] W.J. Kim, C.W. An, Y.S. Kim and S.I. Hong, "Mechanical properties and microstructure of an AZ61 Mg alloy produced by equal channel angular pressing," Scripta Materialia 47 (2002) 39-44.

[13] S. Seipp, M. F.-X. Wagner, K. Hockauf, I. Schneider, L.W. Meyer and M. Hockauf, "Microstructure, crystallographic texture and mechanical properties of the magnesium alloy AZ31B after different routes of thermo-mechanical processing," Int. J. Plasticity 35 (2012) 155-166.

[14] A.M. Twier, J.D. Robson, G.W. Lorimer, and P. Rogers, "Texture development in the extruded Magnesium-Yttrium-Gadolinium alloy Elektron 675," 8th International Conference on Magnesium Alloys and their Applications, WILEY-VCH Verlag GmbH, Germany, 2009.

[15] A.M. Twier, J.D. Robson, G.W. Lorimer, and P. Rogers, "A study of microstructure of cast and extruded Elektron 675," 8th International Conference on Magnesium Alloys and their Applications, WILEY-VCH Verlag GmbH, Germany, 2009.

[16] F. Zhang, K-X. Zhang, C-W. Tan, X-D. Yu, H-L. Ma, F-C. Wand, and H-N. Cai, "Microstructure and mechanical properties of Mg-Gd-Y-Zr alloy processed by equal channel angular pressing," Trans. Nonferrous Met. Soc. China 21 (2011) 2140-2146.

[17] M. Eichhorst, L.W. Meyer, and N. Herzig, Nordmetall GmbH, unpublished research, 2014.

[18] S.X. Ding, W.T. Lee, C.P. Chang, L.W. Chang, and P.W. Kao, "Improvement of strength of magnesium alloy processed by equal channel angular extrusion," Scripta Materialia 59 (2008) 1006-1009.

[19] M. Al-Maharbi, I. Karaman, I.J. Beyerlein, D.C. Foley, K.T. Hartwig, L.J. Kecskes, and S.N. Mathaudhu, "Microstructure, crystallographic texture, and plastic anisotropy evolution in an $\mathrm{Mg}$ alloy during equal channel angular extrusion processing," Materials Science and Engineering A 528 (2011) 7616- 7627. 
[20] D.C. Foley, M. Al-Maharbi, K.T. Hartwig, I. Karaman, L.J. Kecskes and S.N. Mathaudhu, "Grain refinement vs. crystallographic texture: Mechanical anisotropy in a magnesium alloy," Scripta Materialia 64 (2011) 193-196.

[21] S.M. Razavi, D.C. Foley, I. Karaman, K.T. Hartwig, O. Duygulu, L.J. Kecskes, S.N. Mathaudhu, and V.H. Hammond, "Effect of grain size on prismatic slip in Mg3Al-1Zn alloy," Scripta Materialia 67 (2012) 439-442.

[22] F-D. Dumitru, N. Ghiban, and G. Gurău, "Structural characterizations of ZK60 subjected to ECAP Process - Route A," U.P.B. Sci. Bulletin Series B 75 (2013) 201208.

[23] Y. He, Q. Pan, Y. Qin, X. Liu, W. Li, Y. Chiu, and J.J. Chen, "Microstructure and mechanical properties of ZK60 alloy processed by two-step equal channel angular pressing," J Alloys and Compounds 492 (2010) 605-610.

[24] F.-D.Dumitru, O.F.Higuera-Cobos, and J.M.Cabrera, "ZK60 alloy processed by ECAP: Microstructural, physical, and mechanical characterization," Materials Science and Engineering A 594 (2014) 32-39.

[25] S.R. Agnew, J.A. Horton, T.M. Lillo, and D.W. Brown, "Enhanced ductility in strongly textured magnesium produced by equal channel angular pressing," Scripta Materialia 50 (2004) 377-381.

[26] M. Gzyl, A. Rosochowski, S. Boczkal, and L. Olejnik, "The role of microstructure and texture in controlling mechanical properties of $A Z 31 B$ magnesium alloy processed by I-ECAP," Materials Science and Engineering A 638 (2015) 20-29.

[27] S. Kleiner and P.J. Uggowitzer, "Mechanical anisotropy of extruded Mg-6\% Al-1\% Zn alloy," Materials Science and Engineering A 379 (2004) 258-263.

[28] X. Li, W. Qi, K. Zheng, and N. Zhou, "Enhanced strength and ductility of MgGd-Y-Zr alloys by secondary extrusion," J Magnesium and Alloys 1 (2013) 54-63.

[29] R. Lapovok, "The role of back-pressure in equal channel angular extrusion," J of Materials Science 40 (2005) 341-346.

[30] T. Mukai, T. Mohri, M. Mabuchi, M. Nakamura, K. Ishikawa, K. Higashi, "Experimental study of a structural magnesium alloy with high absorption energy under dynamic loading," Scripta Materialia 39 (1998) 1249-1253. 
[31] S. Agnew, W. Whittington, A. Oppedal, H. El Kadiri, M. Shaeffer, K.T. Ramesh, J. Bhattacharyya, R. DeLorme, and B. Davis, "Dynamic behavior of a rare-earthcontaining Mg alloy, WE43B-T5, plate with comparison to conventional alloy, AM30F," JOM 66 (2014) 277-290.

[32] I. Ulacia, N.V. Dudamell, F. Gálvez, S. Yi, M.T. Pérez-Prado, and I. Hurtado, "Mechanical behavior and microstructural evolution of a Mg AZ31 sheet at dynamic strain rates," Acta Materialia 58 (2010) 2988-2998.

[33] M.R. Barnett, "A Taylor model based description of the proof stress of magnesium AZ31 during hot working," Metallurgical and Materials Transactions 34A (2003) 1799-1806.

[34] Y. Suyuan, "The microstructure features and the deformation mechanism of a fine grained magnesium alloy under dynamic loading," Reviews on Advanced Materials Science 25 (2010) 122-127.

[35] M. A. Meyers, Dynamic Behavior of Materials, Wiley and Sons, New York, 1994.

[36] V. Livescu, C.M. Cady, E.K. Cerreta, B.L. Henrie, and G.T. Gray III, "The high strain rate deformation behavior of high purity magnesium and AZ31B magnesium alloy," Magnesium Technology 2006, ed. A.A. Luo, N.R. Neelameggham, and R.S. Beals, TMS, 2006, 153-158.

[37] G.T. Gray III, "High strain rate deformation: Mechanical behavior and deformation substructures induced," Annual Review of Materials Research 42 (2012) 285-303. 